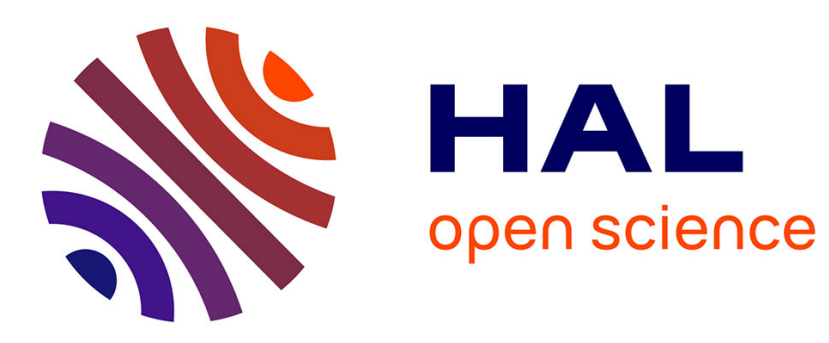

\title{
Realization of an Asymmetric Interdigitated Electrochemical Micro-Capacitor Based on Carbon Nanotubes and Manganese Oxide
}

Ty Mai Dinh, Fabien Mesnilgrente, Véronique Conédéra, Nana Amponsah Kyeremateng, David Pech

\section{To cite this version:}

Ty Mai Dinh, Fabien Mesnilgrente, Véronique Conédéra, Nana Amponsah Kyeremateng, David Pech. Realization of an Asymmetric Interdigitated Electrochemical Micro-Capacitor Based on Carbon Nanotubes and Manganese Oxide. Journal of The Electrochemical Society, 2015, 162 (10), pp.A2016 A2020. 10.1149/2.0431510jes . hal-01872846

\section{HAL Id: hal-01872846 \\ https://hal.laas.fr/hal-01872846}

Submitted on 12 Sep 2018

HAL is a multi-disciplinary open access archive for the deposit and dissemination of scientific research documents, whether they are published or not. The documents may come from teaching and research institutions in France or abroad, or from public or private research centers.
L'archive ouverte pluridisciplinaire HAL, est destinée au dépôt et à la diffusion de documents scientifiques de niveau recherche, publiés ou non, émanant des établissements d'enseignement et de recherche français ou étrangers, des laboratoires publics ou privés. 


\title{
(4t) Realization of an Asymmetric Interdigitated Electrochemical
Micro-Capacitor Based on Carbon Nanotubes and Manganese
Oxide
}

Ty Mai Dinh,,${ }^{\mathrm{a}, \mathrm{b}}$ Fabien Mesnilgrente, ${ }^{\mathrm{a}}$ Véronique Conédéra, ${ }^{\mathrm{a}}$ Nana Amponsah Kyeremateng, ${ }^{\mathrm{a}, \mathrm{b}}$ and David Pech ${ }^{\mathrm{a}, \mathrm{b}, *, \mathrm{z}}$

${ }^{a}$ CNRS, LAAS, F-31400 Toulouse, France

${ }^{b}$ Université de Toulouse, LAAS, F-31400 Toulouse, France

\begin{abstract}
Asymmetric interdigitated micro-supercapacitors with high resolution, dedicated to energy storage in embedded micro-systems, are fabricated using a simple micro-fabrication process based on the inkjet printing and electrolytic deposition techniques. The process is optimized to realize a carbon nanotubes (cathode)/manganese oxide (anode) hybrid micro-device with a resolution of $100 \mu \mathrm{m}$. The cell capacitance reaches a value of $2.4 \mathrm{mF} . \mathrm{cm}^{-2}$. Moreover, the use of the asymmetric configuration allows extending the working voltage of the device from $1 \mathrm{~V}$ to $1.8 \mathrm{~V}$ in an aqueous solution.

(C) The Author(s) 2015. Published by ECS. This is an open access article distributed under the terms of the Creative Commons Attribution 4.0 License (CC BY, http://creativecommons.org/licenses/by/4.0/), which permits unrestricted reuse of the work in any medium, provided the original work is properly cited. [DOI: 10.1149/2.0431510jes] All rights reserved.
\end{abstract}

Manuscript received July 1, 2015. Published July 28, 2015.

The latest development of low-power integrated circuits, together with the decrease of their dimensions, has made embedded systems increasingly popular. Wearable electronic devices can be integrated in everyday-use objects, and the emerging technology of wireless sensor networks will lead to a wide range of new applications including environmental monitoring, surveillance or assisted medical care. ${ }^{1}$ In order to be energetically autonomous, efficient energy harvesting and on-board energy storage technologies are still critical issues for embedded micro-systems.

Supercapacitors show very interesting characteristics when it comes to these applications, thanks to their extended lifetimes and high power densities. In the past few years, the integration of low profile supercapacitors on a chip have been the subject of intense research and various types of symmetrical micro-supercapacitors, based on aqueous or organic electrolytes, have been realized..$^{2-6}$ Aqueous electrolytes usually give lower internal resistance and higher specific capacitance than organic electrolytes, are environmentally friendly, and can be used with pseudo-capacitive materials. ${ }^{7}$ Despite these advantages of aqueous electrolytes, there is a penalty of a restricted operating voltage range, with an upper limit of ca. $1 \mathrm{~V}$ because of inevitable water decomposition in such electrolytes - at higher potentials. This upper limit of operating voltage is lower than that of the organic electrolytes which tends to be greater than $2 \mathrm{~V}$.

An interesting way to extend the cell voltage of aqueous electrolyte-based supercapacitors beyond the thermodynamic limit of water splitting is to design an asymmetric device, consisting of two different electrodes having high overpotentials for hydrogen and/or oxygen evolutions. ${ }^{8}$ Couples of carbonaceous (activated carbon, graphene, carbon black, carbon nanotubes...) and $\mathrm{MnO}_{2}$ materials are one of the representatives of these asymmetric systems. Carbonaceous materials with electrochemical double layer capacitances, usually exhibit low resistance, high stability and cathodic polarizations. ${ }^{9}$ At the positive electrode, the manganese oxide exhibits a high pseudo-capacitance involving various valence states and can sustain an oxygen evolution overpotential in neutral solutions. ${ }^{10,11}$ These materials have been successfully used to widen the potential window of aqueous electrolytes, in order to obtain high energy and power density supercapacitors. ${ }^{12-14}$

Although numerous asymmetric supercapacitors are reported in the literature, there have been very few reports on asymmetric microdevices. ${ }^{15,16} \mathrm{E}$. Eustache et al. have realized an asymmetric electrochemical capacitor micro-device designed with vanadium nitride and nickel oxide, able to cycle up to $1.8 \mathrm{~V}$ with an interesting $3.6 \mathrm{~mJ} . \mathrm{cm}^{-2}$

*Electrochemical Society Active Member.

${ }^{\mathrm{z} E}$-mail: dpech@laas.fr specific energy. ${ }^{17}$ C.C. Liu et al. have reported the fabrication of asymmetric electrochemical micro-capacitors based on carbon nanotubes $(\mathrm{CNT})$ and manganese oxide $\left(\mathrm{MnO}_{x}\right)$ deposited by chemical vapor deposition (CVD) and electrodeposition, respectively. ${ }^{18}$ Although their $\mathrm{CNT} / \mathrm{MnO}_{x}$ micro-devices exhibited very good power and energy performances, they were only tested up to $1 \mathrm{~V}$ because of unbalanced charge between negative and positive electrodes.

In the present work, we demonstrate the scalable fabrication of a new type of asymmetric planar interdigitated electrochemical microcapacitor, using oxidized multi-walled carbon nanotubes and manganese oxide as the negative and positive electrodes, respectively. The process, based on the inkjet printing technology, followed by an anodic electrodeposition technique, provides an easy way to balance, with very few technological steps, the charge of the cathode and the anode. The resulting micro-devices are able to cycle up to $1.8 \mathrm{~V}$ in aqueous $\mathrm{Na}_{2} \mathrm{SO}_{4}$ electrolyte.

\section{Experimental}

Patterning of the interdigitated current collectors. - Interdigitated patterns of Au current collectors on oxidized silicon wafers were prepared using the lift-off process. An insulating layer of $\mathrm{SiO}_{2}(500 \mathrm{~nm})$ was first thermally grown on the silicon wafer, followed by a spincoating of a negative nLOF photoresist layer. The photoresist was then selectively exposed to UV light and placed in a specific developer solution (MF-CD26 containing 1-5\% tetramethylammonium hydroxide in de-ionized water) to remove the unexposed parts, replicating the inverse mask pattern on the photoresist film. The current collector (400 $\mathrm{nm} \mathrm{Au}$ ) was then deposited all over the substrate, using evaporation. Prior to the deposition of the current collector, pre-coating of $100 \mathrm{~nm}$ Ti was done to promote the adhesion of the current collector on the substrate. The wafer was then washed by acetone to remove the photoresist and the metal on top of it, leaving only the Ti/Au which was deposited directly on the substrate. The current collectors were then annealed at $250^{\circ} \mathrm{C}$ for $20 \mathrm{~min}$ in $\mathrm{N}_{2}$.

Preparation of the electrodes. - The multiwalled-carbon nanotubes (MWCNTs, Nanostructured \& Amorphous Materials, Inc., $>97.46 \%$ ) were oxidized in a 15.5 mol. $\mathrm{L}^{-1} \mathrm{HNO}_{3}$ aqueous solution at $120^{\circ} \mathrm{C}$ and kept under constant stirring for $8 \mathrm{~h} .{ }^{19}$ The obtained oxidized multiwalled-carbon nanotubes (O-MWCNTs) were then rinsed in water followed by ethanol; and filtered using a $0.2 \mu \mathrm{m}$ cellulose membrane. A stable suspension of $500 \mathrm{mg} . \mathrm{L}^{-1}$ of O-MWCNTs in de-ionized water was prepared using ultrasonication dispersion for $1 \mathrm{~h}(-35.7 \mathrm{mV}$ zeta potential for an average particle size of $131.5 \mathrm{~nm})^{20}$ and selectively projected onto the interdigitated gold fingers using an AltaDrop equipment from Altatech. For this purpose, a 
a)

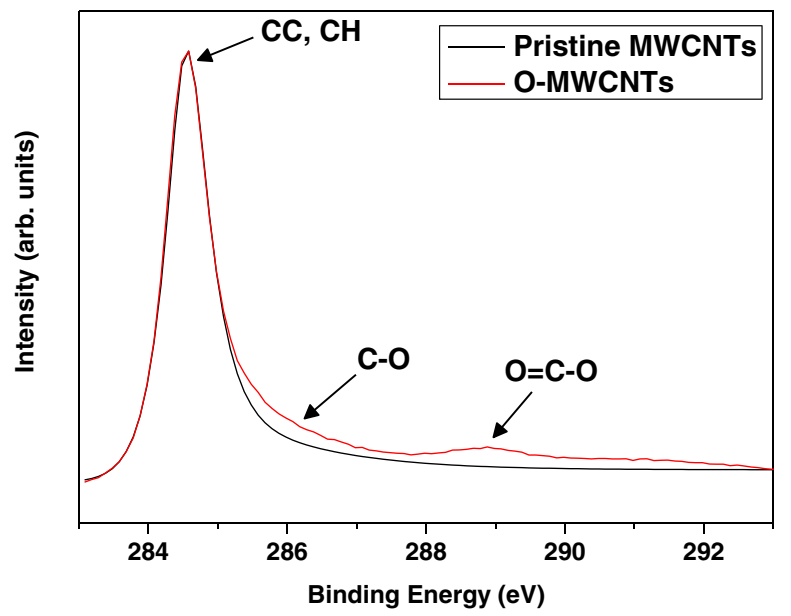

b)

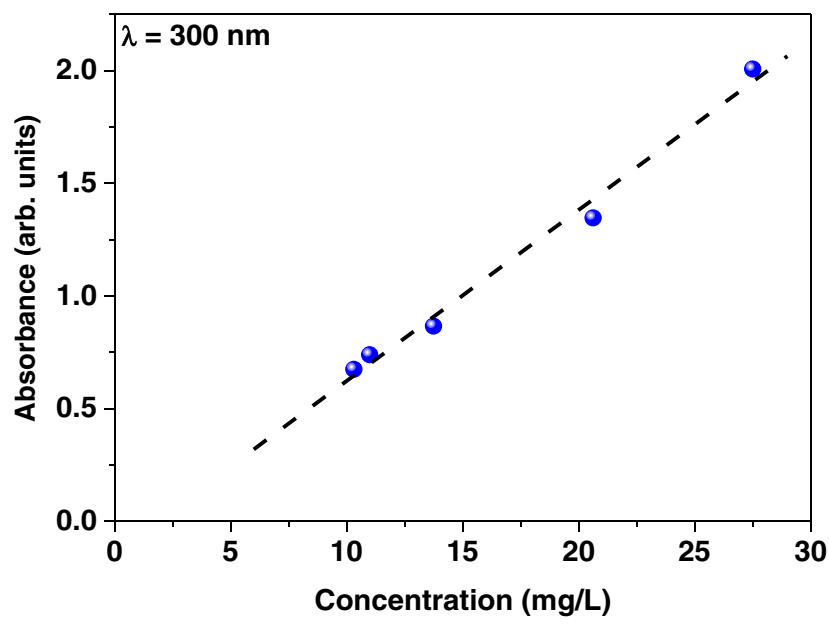

c)

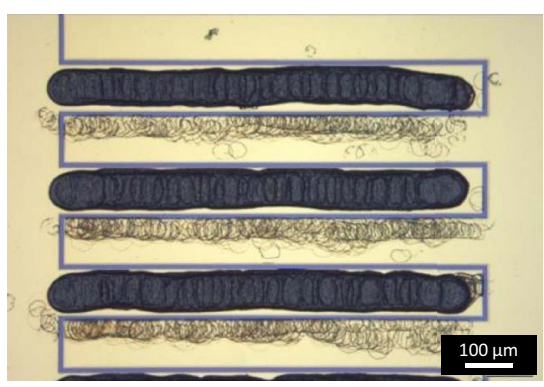

d)

e)
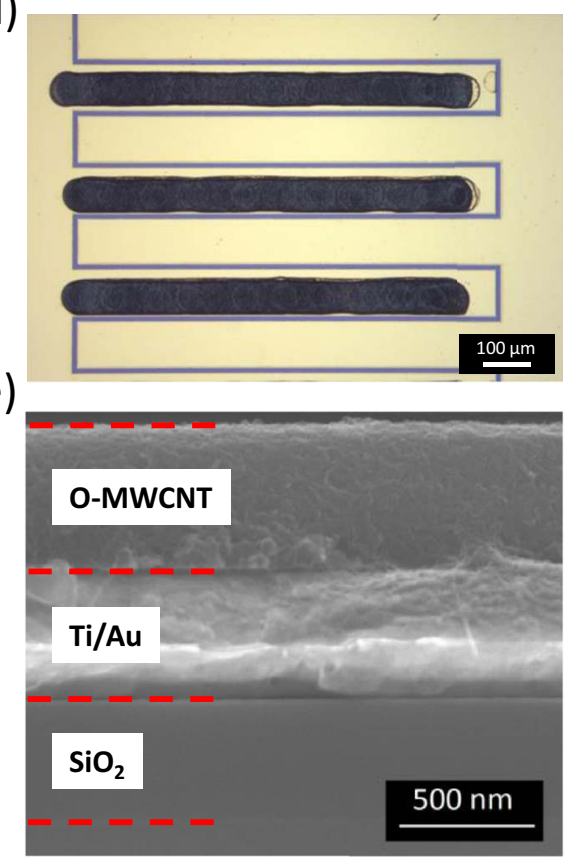

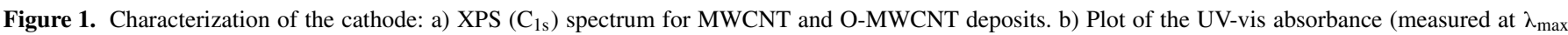

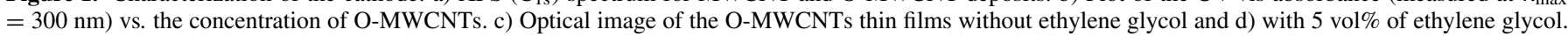
e) Cross-section image of the oxidized MWCNTs deposit.

hydrophobic surface functionalization of the inter-finger spacing silicon dioxide was performed by molecular vapor deposition of a selfassembled monolayer of perfluorodecyltrichlorosilane (FDTS) using a SPD (Surface Preparation and Deposition) from MEMSSTAR. The gold was therefore more hydrophilic, i.e. with a higher surface energy, than the surrounding hydrophobic silica surface, allowing thus the deposition of the ink onto the gold electrodes acting as current collectors. The manganese oxide was subsequently electrodeposited onto the other electrode from a $0.25 \mathrm{M} \mathrm{MnSO}_{4} \cdot x \mathrm{H}_{2} \mathrm{O}$ aqueous solution, by applying a potential of $0.9 \mathrm{~V}$ vs. $\mathrm{Ag} / \mathrm{AgCl}$ as described elsewhere. ${ }^{21}$

Characterization methods.- X-ray-diffraction studies were carried out at room temperature using a D8 Discover Bruker (Karlsruhe, Germany) diffractometer with $\mathrm{Cu} \mathrm{K \alpha}$ radiation (1.5406 $\AA$ ). Scanning electron microscopy (SEM) was performed using a Hitachi S-4800 field-emission electron microscope. The surface chemical composition of the O-MWCNTs was determined by XRay Photoelectron Spectroscopy (XPS) using a Thermo Scientific Spectrometer operating with a monochromatic $A l K \alpha \mathrm{X}$-ray source $(1486.6 \mathrm{eV})$. The concentration of the O-MWCNTs in solution was determined using a Thermo Scientific NanoDrop 2000c UV-Vis spectrophotometer.
Electrochemical measurements. - The electrode materials and the asymmetric micro-devices were characterized in de-aerated $0.5 \mathrm{M}$ $\mathrm{Na}_{2} \mathrm{SO}_{4}$ electrolyte using a VMP3 potentiostat/galvanostat from Biologic. In the three-electrode configuration, an $\mathrm{Ag} / \mathrm{AgCl}(\mathrm{KCl} 3 \mathrm{M}$ sat. $\mathrm{AgCl}$ ) and a twisted platinum wire were used as the reference and counter electrodes, respectively. Electrochemical impedance spectroscopy (EIS) was carried out in the frequency range between $100 \mathrm{kHz}$ to $10 \mathrm{mHz}$ with a $10 \mathrm{mV}$ AC voltage amplitude.

\section{Results and Discussion}

The carbon nanotubes cathodes have been deposited by a process based on the inkjet printing technology. In order to have efficient ink-jet printability, good particle-dispersion stability of the ink is necessary. The MWCNTs have been therefore oxidized in nitric acid to obtain hydrophilic carboxylic groups and improve the dispersion of the powder in polar solvents. The XPS analysis of $\mathrm{C}_{1 \mathrm{~s}}$ spectra (Fig. 1a) shows detailed surface functional groups on the carbon nanotubes. A main peak, centered at $284.5 \mathrm{eV}$ and assigned to $\mathrm{sp}^{2}$-hybridized carbon atoms, is observed for the pristine MWCNTs. Using this peak as a reference, the $\mathrm{C}_{1 \mathrm{~s}}$ peaks of the oxidized MWCNTs are attributed to $\mathrm{C}-\mathrm{O}$ bond $(286.3 \mathrm{eV})$ and carboxyl $\mathrm{O}=\mathrm{C}-\mathrm{OH}(289 \mathrm{eV})$. The presence of these peaks indicates the effective $\mathrm{HNO}_{3}$ acidic treatment to introduce carboxylic groups $(-\mathrm{COOH})$ on the MWCNTs. 
a)

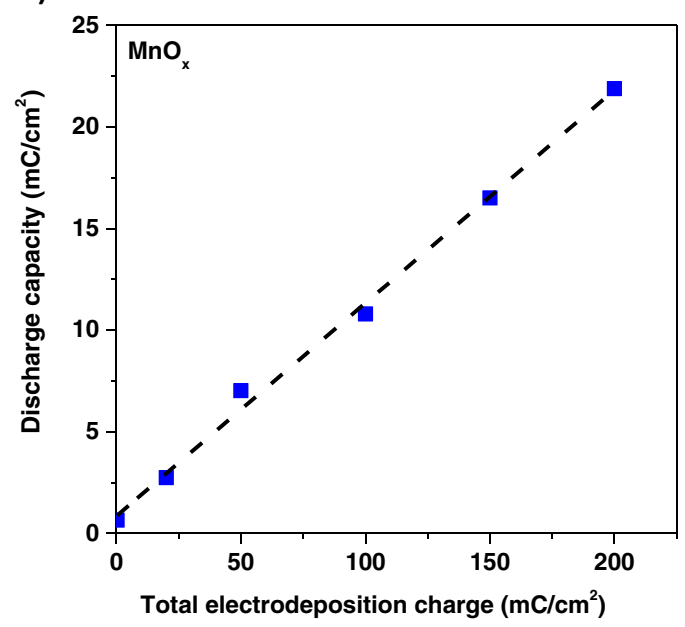

b)

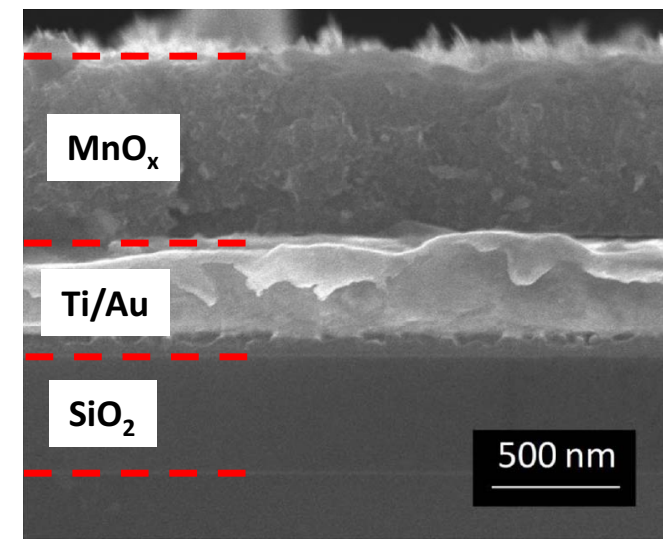

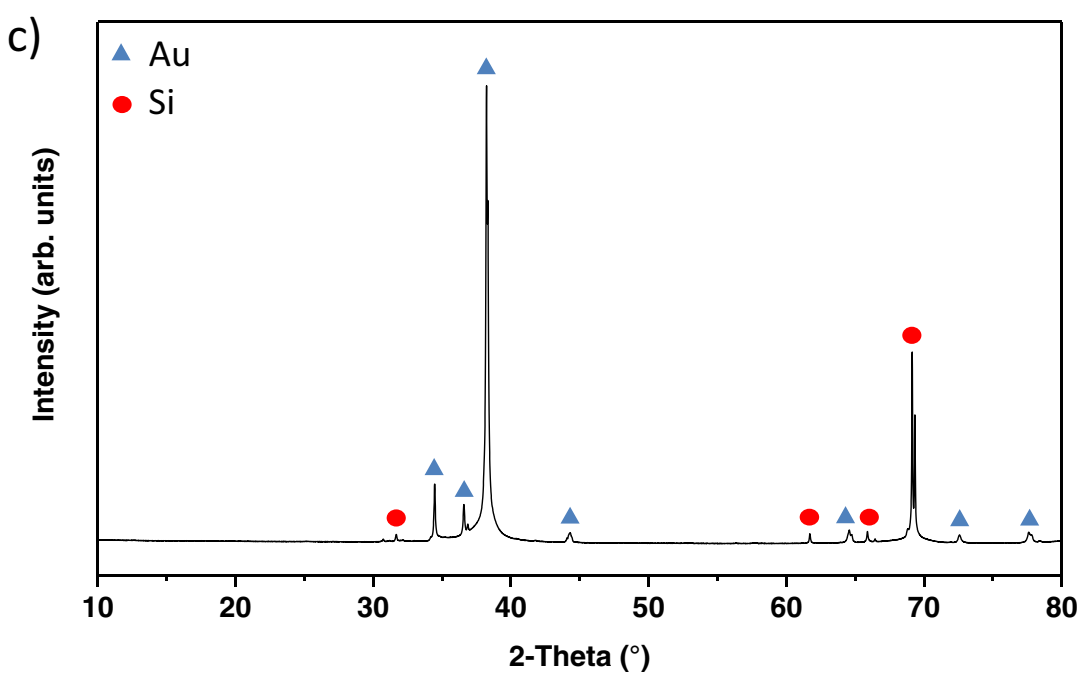

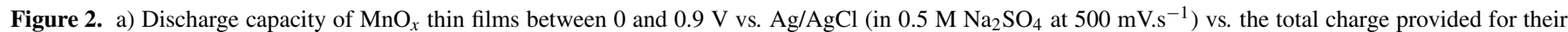

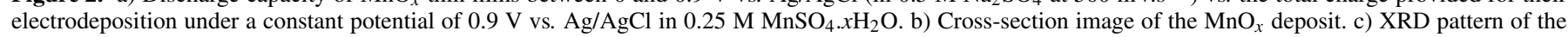
electrodeposited $\mathrm{MnO}_{x}$ on the substrate.

During the preparation of the suspensions, some sedimentation of O-MWCNTs bundles has been observed. In order to determine the real concentration of the O-MWCNTs in the ink, a series of standard suspensions of oxidized carbon nanotubes in de-ionized water, with very low concentrations (to ensure a total dispersion), has been prepared. For each solution, the absorbance at the wavelength of the strongest absorption $\left(\lambda_{\max } \sim 300 \mathrm{~nm}\right)$ is measured using UV-visible absorption spectroscopy. The linear dependence of the intensity of the absorbance peak with the concentration of oxidized carbon nanotubes (Fig. 1b) indicates that the Beer's law is obeyed. Using this calibration curve, the concentration of our ink was estimated to be $218 \mathrm{mg} . \mathrm{L}^{-1}$.

This suspension was inkjet-printed on one interdigitated electrode. The thickness of the deposit was not homogeneous and satellite drops were observed on the second electrode (which may lead to a short circuit) (Fig. 1c). This suspension has been therefore mixed with $5 \mathrm{vol} \%$ ethylene glycol, in order to adjust the viscosity for improved flow and ejection properties. As shown in Figure 1d, the small amount of ethylene glycol in the ink enabled a spatially selective deposition of the O-MWCNTs droplets, with a homogeneous thickness of $500 \mathrm{~nm}$ after 40 inkjet passages (Fig. 1e). The total voltammetric charge of this electrode, determined after deposition, is $200 \mathrm{mC} . \mathrm{cm}^{-2}$.
To ensure a suitable charge balance between the cathode and the anode, the total charge supplied for the $\mathrm{MnO}_{x}$ electrodeposition has been varied. As shown in Figure 2a, a linear relationship is observed between the total charge provided for the electrodeposition of $\mathrm{MnO}_{x}$ and the voltammetric charge of the obtained films; the discharge capacity of the $\mathrm{MnO}_{x}$ electrode can be therefore accurately controlled by the total charge provided for its electrodeposition. Consequently, the $\mathrm{MnO}_{x}$ deposition time has been appropriately adjusted to provide $200 \mathrm{mC} . \mathrm{cm}^{-2}$; as shown in Figure 2b, the corresponding thickness of $\mathrm{MnO}_{x}$, for such value, is around $600 \mathrm{~nm}$. Figure $2 \mathrm{c}$ shows the $\mathrm{X}$-ray diffraction pattern of the electrodeposited $\mathrm{MnO}_{x}$ anode. Only the diffraction peaks of the substrate $(\mathrm{Au}$ and $\mathrm{Si}$ ) are observed, indicating an amorphous phase of the $\mathrm{MnO}_{x}$ deposit. Figure 3 shows an optical image of the resulting micro-device. The footprint area is $2.2 \mathrm{~mm}^{2}$ and no short circuit is observed between adjacent interdigitated fingers separated by $100 \mu \mathrm{m}$ interspace. According to our previous research, such resolution is important to minimize the equivalent series resistance (ESR) of the device. ${ }^{22}$

Figure 4 shows the normalized cyclic voltammogram (CV) of the O-MWCNTs (red) and $\mathrm{MnO}_{x}$ (blue) performed on a macroscopic electrode $\left(1 \mathrm{~cm}^{2}\right)$ in a de-aerated $0.5 \mathrm{M} \mathrm{Na}_{2} \mathrm{SO}_{4}$ solution at 500 $\mathrm{mV} \cdot \mathrm{s}^{-1}$. The O-MWCNT is cycled between -1000 and $+311 \mathrm{mV}$ vs. $\mathrm{Ag} / \mathrm{AgCl}$. Within this potential window, the shape of the $\mathrm{CV}$ is 
a)

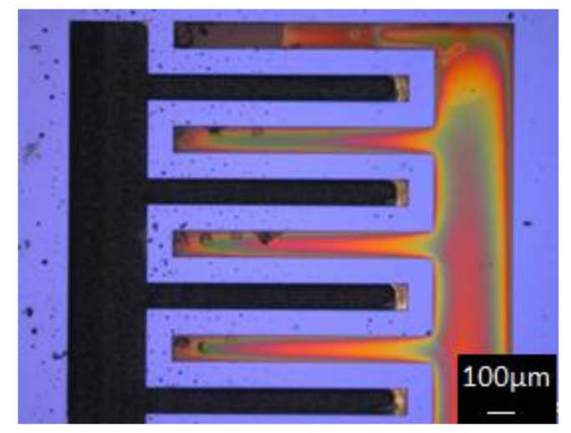

b)

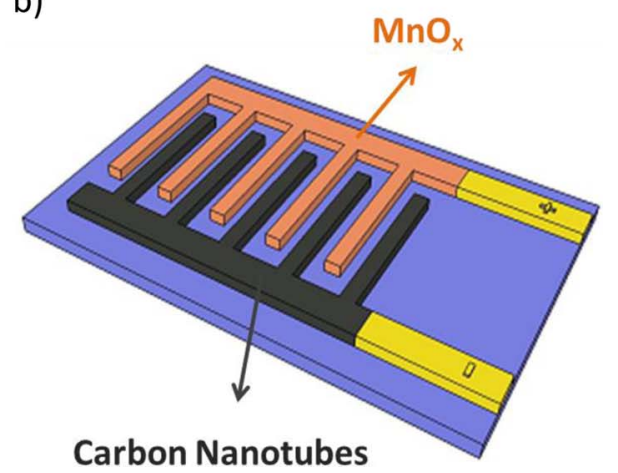

Figure 3. a) Optical image and b) schematic of the asymmetric micro-supercapacitor.

pseudo-rectangular, as expected for a material displaying capacitive behavior. A redox couple at $-100 /-300 \mathrm{mV}$ vs. $\mathrm{Ag} / \mathrm{AgCl}$ is also observed; this couple, however, involves the oxidation/reduction of surface functional groups generically represented by: ${ }^{23}$

$$
=\mathrm{C}=\mathrm{O}+\mathrm{H}^{+}+\mathrm{e}^{-} \leftrightarrow=\mathrm{C}-\mathrm{OH}
$$

In an aqueous electrolyte, this redox reaction enhances the total capacitance of the cathode by introducing a pseudo-capacitive contribution to the predominant double-layer capacity of the MWCNTs. Another $\mathrm{CV}$ was recorded, with the same conditions, for the $\mathrm{MnO}_{x}$ electrode (Fig. 4: blue curve); and it can be noticed that, the range of the electrochemical window - over which a pseudo-capacitive behavior is observed - is shifted toward more positive potentials (up to $+900 \mathrm{mV}$ vs. $\mathrm{Ag} / \mathrm{AgCl}$ ) compared to the O-MWCNTs. These two electrodes have therefore well-separated potential windows and are appropriate to realize an asymmetric device with an extended cell voltage.

Cyclic voltammograms performed at $500 \mathrm{mV} . \mathrm{s}^{-1}$ and recorded at different potential windows are shown in Figure 5a for the asymmetric micro-supercapacitor. A rectangular shape is obtained for potential windows inferior to $1.8 \mathrm{~V}$. At $1.9 \mathrm{~V}$, a small oxidation peak is indeed observed due to water decomposition, limiting the cell voltage of the component. The cell capacitance for this micro-device is $2.4 \mathrm{mF} . \mathrm{cm}^{-2}$ at $500 \mathrm{mV} . \mathrm{s}^{-1}$, which is higher than the value reported in our previous work for inkjet-printing electrochemical double-layer micro-capacitors. ${ }^{24}$ The maximal specific energy we can obtain for the micro-device for the $1.8 \mathrm{~V}$ potential range is $3.9 \mathrm{~mJ}^{-\mathrm{cm}^{-2}}$. Figure $5 \mathrm{~b}$ shows the $\mathrm{CV}$ behavior of each individual electrode in a threeelectrode setup (vs. $\mathrm{Ag} / \mathrm{AgCl}$ ) when the micro-device is cycled up to $1.8 \mathrm{~V}$. The O-MWCNT interdigitated electrode operates in the range

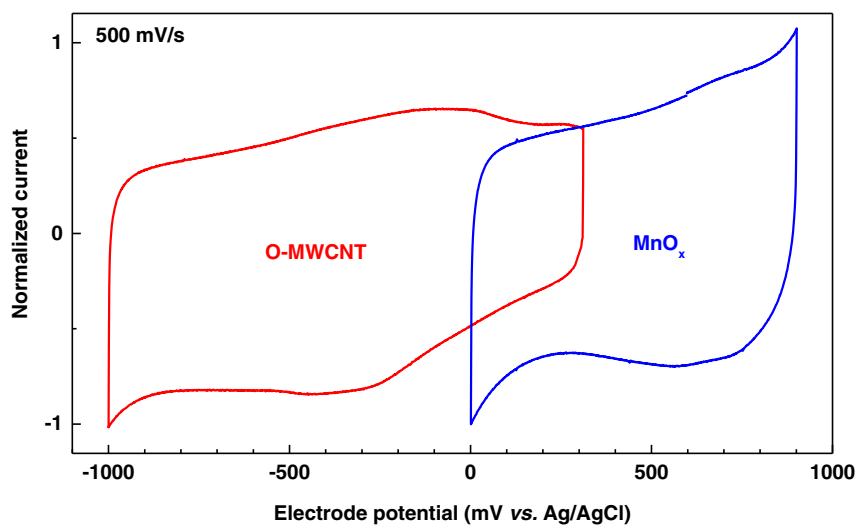

Figure 4. Normalized cyclic voltammograms of the O-MWCNT (red) and $\mathrm{MnO}_{x}$ (blue) performed on macroscopic electrodes $\left(1 \mathrm{~cm}^{2}\right)$ in de-aerated $0.5 \mathrm{M} \mathrm{Na}_{2} \mathrm{SO}_{4}$ at $500 \mathrm{mV} . \mathrm{s}^{-1}$. of $1.06 \mathrm{~V}$ (from $+110 \mathrm{mV}$ to $-951 \mathrm{mV}$ vs. $\mathrm{Ag} / \mathrm{AgCl}$ ) while the $\mathrm{MnO}_{x}$ interdigitated electrode operates in the potential range of 0.75 $\mathrm{V}$ (from $+110 \mathrm{mV}$ to $+858 \mathrm{mV}$ vs. $\mathrm{Ag} / \mathrm{AgCl}$ ). Compared with symmetric micro-supercapacitors, each electrode can now operate in its complete potential window in an aqueous solution.

The frequency behavior has been studied by EIS at a bias voltage of $0 \mathrm{~V}$. Figure 6 shows the Nyquist and Bode plots of the asymmetric micro-supercapacitor. From the Nyquist plot (Fig. 6a), two distinct regions, dependent on the frequency range, can be observed. From the high frequency part, an equivalent series resistance of about $1.2 \Omega \mathrm{cm}^{2}$ is estimated for the micro-device. In the low frequency region, the spectrum reveals, as expected, a capacitive behavior
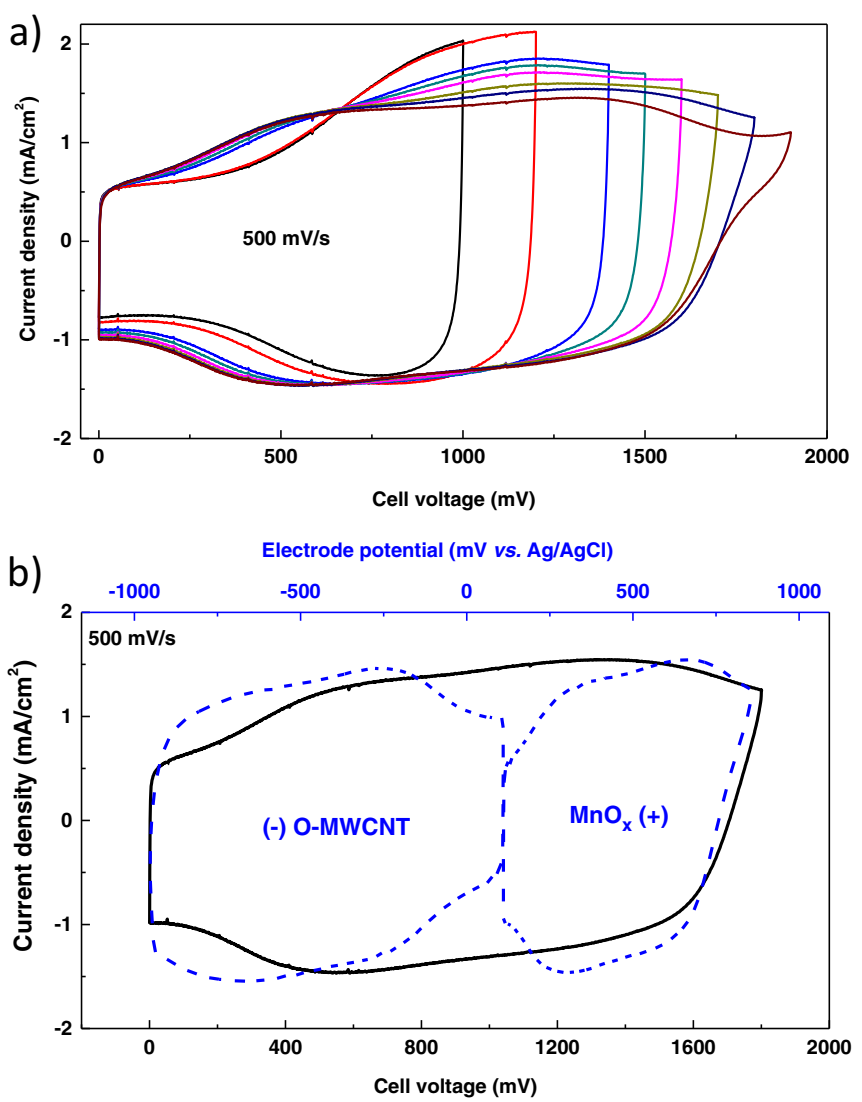

Figure 5. Cyclic voltammograms of a) the O-MWCNT/MnO ${ }_{x}$ asymmetric microsupercapacitor with different cell voltages in a $0.5 \mathrm{M} \mathrm{Na}_{2} \mathrm{SO}_{4}$ solution, and $\mathrm{b}$ ) of the individual electrodes vs. $\mathrm{Ag} / \mathrm{AgCl}$ (blue) when the micro-device is cycled at $1.8 \mathrm{~V}$ (black); 


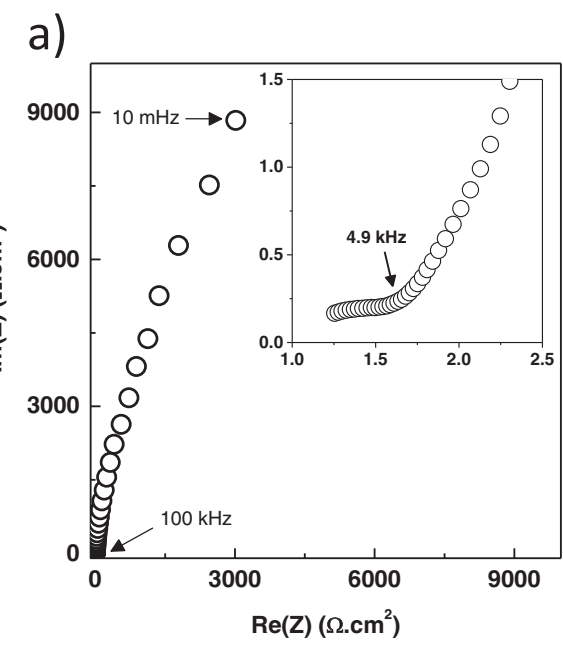

Figure 6. a) Nyquist and b) Bode plot of the asymmetric micro-device.

(increasing of the imaginary part with decreasing frequency) associated with a slight leak current (as can be seen from the phase angle lower than $90^{\circ}$ : Fig. 6b) probably due to the surface functional groups of the O-MWCNTs. Taking into account the ESR over 1.8 $\mathrm{V}$, the maximum specific power reaches a value of $675 \mathrm{~mW} . \mathrm{cm}^{-2}$, which is a rather high value compared with literature. ${ }^{25}$ The combination of the inkjet printing technology with the FDTS treatment, followed by an anodic electrodeposition technique provides therefore an interesting approach to obtain high-resolution interdigitated microsupercapacitors, with very promising performance characteristics.

\section{Conclusions}

In the present study, a microstructured asymmetric electrochemical capacitor, based on carbon nanotubes and manganese oxide, was successfully prepared. The process describes an easy, simple and scalable way to integrate the electrode materials on the chip with an accurate charge balancing between the cathode and the anode. A high specific capacitance of about $2.4 \mathrm{mF} . \mathrm{cm}^{-2}$ was obtained for the micro-cell, which was able to cycle up to $1.8 \mathrm{~V}$ in an aqueous electrolyte. The specific energy and power density was consequently increased by a factor of 4 compared with a symmetric micro-device operating at $0.9 \mathrm{~V}$. These results are very promising and demonstrate the attractive approach of coupling the inkjet-printing and electrodeposition techniques for the elaboration of integrated micro-supercapacitors on $\mathrm{Si}$ substrates to address the need for micro-scale energy storage. We will consider, in future work, the use of a hydrogel as an electrolyte in order to have all-solid-state micro-supercapacitors with improved electrochemical performances and lower leakage current.

\section{Acknowledgments}

This work was partly supported by the French RENATECH network and financially supported by the French National Research Agency (ANR) through the MIDISTOCK project (ANR-11-JS090018).

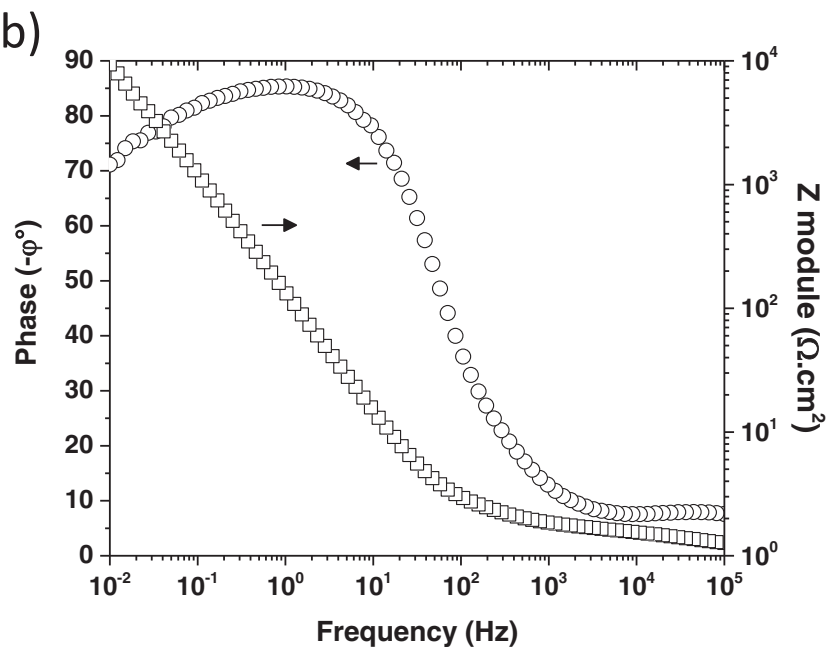

\section{References}

1. J. G. Koomey, H. S. Matthews, and E. Williams, Annu. Rev. Environ. Resour, 38, 17.1 (2013).

2. D. Pech, M. Brunet, H. Durou, P. Huang, V. Mochalin, Y. Gogotsi, P. L. Taberna, and P. Simon, Nat. Nanotechnol., 5, 651 (2010).

3. H. Durou, D. Pech, D. Colin, P. Simon, P. L. Taberna, and M. Brunet, Microsyst. Technol., 18, 467 (2012).

4. P. Huang, M. Héon, D. Pech, M. Brunet, P. L. Taberna, Y. Gogotsi, S. Lofland, J. D. Hettinger, and P. Simon, J. Power Sources, 225, 240 (2013).

5. P. Huang, D. Pech, R. Lin, J. K. M. McDonough Brunet, P. L. Taberna, Y. Gogotsi, and P. Simon, Electrochem. Commun., 36, 53 (2013).

6. T. M. Dinh, K. Armstrong, D. Guay, and D. Pech, J. Mater. Chem. A, 2, 7170 (2014).

7. T. M. Dinh, A. Achour, S. Vizireanu, G. Dinescu, L. Nistor, K. Armstrong, D. Guay, and D. Pech, Nano Energy, 10, 288 (2014).

8. T. H. Wu, Y. H. Chu, C. C. Hu, and L. J. Hardwick, Electrochem. Commun., 27, 81 (2013).

9. D. Qu, J. Appl. Electrochem., 39, 867 (2009).

10. A. M. Chreitzbeeg and W. C. Vosburgh, J. Electrochem. Soc., 104, 1 (1957).

11. J. Wei, N. Nagarajan, and I. Zhitomirsky, J. Mater. Process. Tech., 186, 356 (2007).

12. M. Toupin, T. Brousse, and D. Bélanger, Chem. Mater, 16, 3184 (2004).

13. J. W. Long, D. Bélanger, T. Brousse, W. Sugimoto, M. B. Sassin, and O. Crosnier, MRS Bull., 36, 513 (2011).

14. X. Zhang, X. Sun, H. Zhang, D. Zhang, and Y. Ma, Mater. Chem. Phys., 137, 290 (2012).

15. C. C. Chen, D. S. Tsai, W. H. Chung, K. Y. Lee, Y. M. Chen, and Y. S. Huang, J. Power Sources, 205, 510 (2012).

16. C. Shen, X. Wang, S. Li, J. Wang, W. Zhang, and F. Kang, J. Power Sources, 234 , 302 (2013).

17. E. Eustache, R. Frappier, R. L. Porto, S. Bouhtiyya, J. F. Pierson, and T. Brousse, Electrochem. Commun., 28, 104 (2013).

18. C. C. Liu, D. S. Tsai, W. H. Chung, K. W. Li, K. Y. Lee, and Y. S. Huang, J. Power Sources, 196, 5761 (2011).

19. S. Osswald, M. Havel, and Y. Gogotsi, J. Raman Spectrosc., 38, 728 (2007)

20. T. M. Dinh, D. Pech, M. Brunet, and A. Achour, J. Phys.: Conf. Ser, 476, 012106 (2013).

21. S. L. Kuo and N. L. Wu, J. Electrochem. Soc., 153, A1317 (2006).

22. D. Pech, M. Brunet, T. M. Dinh, K. Armstrong, J. Gaudet, and D. Guay, J. Power Sources, 230, 230 (2013).

23. J. N. Barisci, G. G. Wallace, and R. H. Baughman, J. Electroanal. Chem., 488, 92 (2000).

24. D. Pech, M. Brunet, P. L. Taberna, P. Simon, N. Fabre, F. Mesnilgrente, V. Conédéra, and H. Durou, J. Power Sources, 195, 1266 (2010).

25. M. Beidaghi and Y. Gogotsi, Energy Environ. Sci., 7, 867 (2014). 